\title{
O Sensoriamento Remoto aplicado ao Estudo da Desertificação na Região Semiárida do Norte de Minas
} Gerais

The Remote Sensing applied to the desertification study in the Semiarid Region of Northern Minas Gerais

\author{
Jane Bruna de Almeida ${ }^{1}$ \\ Adriana Aparecida Moreira ${ }^{2}$ \\ Fernando Hiago Souza Fernandes ${ }^{3}$ \\ Rodrigo Praes de Almeida ${ }^{4}$ \\ César Vinícius Mendes Nery ${ }^{5}$
}

\footnotetext{
${ }^{1}$ Engenheira Ambiental, Professora Especialista do Instituto Federal do Norte de Minas -IFNMG, Campus Januária, Fazenda São Geraldo, S/N Km 06 . CEP 39480-000. Januária, MG, Brasil.

${ }^{2}$ Mestranda em Sensoriamento Remoto, Universidade Federal do Rio Grande do Sul - UFRGS. Av. Bento Gonçalves, 9500, Campus do Vale. CEP 91501-970. Porto Alegre, RS, Brasil.

${ }^{3}$ Engenheiro Ambiental, Instituto Biotrópicos - Bolsista CNPq, Praça, 937, Campus JK. CEP 39480-000- Januária, MG, Brasil.

${ }^{4}$ Mestrando em Produção Vegetal, Universidade Federal de Minas Gerais - UFMG. Av. Osmane Barbosa, 11.111 - JK. CEP 39404-006. Montes Claros, MG, Brasil.

${ }^{5}$ Engenheiro Agrônomo, Professor M.Sc. das Faculdades Santo Agostinho, Doutorando em Geografia, PUC Minas, AvOsmane Barbosa, 937, Campus JK. CEP 39404-006 - Montes Claros, MG, Brasil.

janebruna6@hotmail.com, moreiradriana00@gmail.com, hiagosf@hotmail.com,rpasax@hotmail.com.br, cvmn@hotmail.com
}

\begin{abstract}
RESUMO - O fenômeno conhecido como desertificação, resulta da degradação das terras nas zonas áridas, semiáridas e subúmidas secas. É consequência do resultado da pressão antrópica sobre o meio como também das variabilidades climáticas. Os danos ambientais gerados por esse processo afetam de forma direta na qualidade de vida da população, fazendo-se necessário a realização de estudos nessas áreas para que os resultados produzidos sirvam de apoio, seja através de medidas de recuperação ou de prevenção. O objetivo deste trabalho é a identificação das áreas susceptíveis à desertificação na região semiárida do Norte do Estado de Minas Gerais, utilizando de técnicas de sensoriamento remoto para caracterizar e avaliar a área. O índice de vegetação (NDVI) produzido a partir da imagem LANDSAT 5 TM foi utilizado para caracterizar a cobertura do solo para os anos de 2001 e 2010. As classes geradas foram quantificadas e comparadas nesses dois anos. Através dos resultados obtidos foi possível verificar o nível de degradação na região e as mudanças na cobertura do solo para os períodos analisados. O estudo indicou uma tendência de crescimento nas áreas em desertificação para a área analisada.
\end{abstract}

Palavras-chave: LANDSAT 5 TM; NDVI; Cobertura do solo.

\begin{abstract}
The phenomenon known as desertification, resulting from the degradation land in arid zones, semi-arid and sub-humid dried. It is consequence of the anthropic effect on the environment as well as climatic variability. Environmental damage caused by this process affect directly population life quality, making it necessary the perform studies in these areas so that the produced outcomes assisting as support, either through recovery or prevention measures. The objective of this work is the identification of susceptible areas to desertification in the Semiarid Region of Northern Minas Gerais, using remote sensing techniques to characterize and evaluate the area. The vegetation index (NDVI) produced from the Landsat 5 TM image was used to characterize the land cover for the years 2001 and 2010. The classes were quantified and compared to both years. From the results obtained was possible to check the degradation level in the region and changes in land cover for the periods analyzed. The study indicated an upward trend of the desertification areas analyzed.
\end{abstract}

Keywords: Landsat 5 TM; NDVI; Land Cover.

\section{INTRODUÇÃO}

O fenômeno conhecido como desertificação, resulta da degradação das terras nas zonas áridas, semiáridas e subúmidas secas. Está associado ao resultado da pressão antrópica sobre o meio como também das variabilidades climáticas.

Para diversos estudiosos do processo, a desertificação se configura como um dos mais graves 
problemas enfrentados pela humanidade, dado que os danos ambientais gerados afetam de forma direta a qualidade de vida da população (PATRÍCIO et al., 2012; SILVA et al., 2011; VIEIRA, 2009).

O termo desertificação foi utilizado pela primeira vez na publicação Climats, Forests et Desertification de l'Áfrique Tropicale, do autor Aubreville (1949) para caracterizar a substituição de florestas tropicais e subtropicais por savanas. Sendo que, anos depois, o mesmo conceito começou a ser utilizado para definir o problema ambiental global devido às condições de seca em regiões da África, tais como Senegal, Mauritânia, Burkina-Faso, Mali, Chade e Sudão.

A desertificação vem representando um alto índice, preocupando a sociedade com o seu avanço. Foi tratado como um problema de âmbito mundial depois que uma grande seca afetou drasticamente o Sahel, na África, de 1968 a 1974, causando a morte de 200.000 (duzentas mil) pessoas e milhões de animais em todo seu território.

Os estudos sobre desertificação se iniciaram no Brasil a partir da década de 70, como parte do Relatório Brasileiro para a Conferência de Nairóbi. O tema de discussão do evento que ficou conhecido como ECO - 92, realizado no Rio de Janeiro, a Convenção de Combate à Desertificação (CCD) foi considerado como um dos principais documentos resultantes desse evento. Posteriormente estudos e programas foram desenvolvidos com o intuito de conter o avanço do processo de desertificação nas regiões semiáridas.

Dentre as ferramentas utilizadas para estudar as áreas atingidas pela desertificação, se destaca o Sensoriamento Remoto, devido à possibilidade de informações geradas e confiança nos resultados obtidos, além da capacidade de uma análise espaço-temporal e do desenvolvimento de modelos para estudos do processo.

No Brasil, parte da sua porção semiárida encontra-se no Norte do Estado de Minas Gerais, incluída como uma área susceptível a desertificação, caracterizada como uma área de baixo índice pluviométrico, distribuição irregular de chuvas e de longos períodos de seca. Além dessas alterações climáticas, apresentam-se na região, fortes sinais de degradação, como o uso ilimitado dos recursos naturais, os desmatamentos, a mineração e agropecuária extensiva, fatores esses, que favorecem a ocorrência do processo de desertificação.

O objetivo do trabalho é estudar áreas susceptíveis à desertificação na região semiárida do Norte de Minas Gerais, utilizando técnicas de Sensoriamento Remoto, possibilitando o mapeamento, delimitação e monitoramento dessas áreas, diagnosticando o nível de degradação nessa região, de forma a contribuir no apoio à contenção do avanço da desertificação.

\section{REFERENCIAL TEÓRICO}

Os processos erosivos nas áreas em desertificação apresentam uma aridez muito severa e uma área periférica que constitui uma faixa transicional subúmida, que podem ser caracterizados por determinados indicadores, tais como: elevação da temperatura média anual; redução progressiva das precipitações; diminuição da média da umidade relativa; aumento da amplitude térmica diária, devido à falta de vapor de água no ar; aumento do escoamento superficial; agravamento do déficit hídrico dos solos e abaixamento do lençol freático.

As Áreas Susceptíveis à Desertificação (ASD) no Brasil foram delimitadas de acordo com os pressupostos da Convenção das Nações Unidas de Combate à Desertificação (CCD), que tomam por base a classificação climática de Thornthwaite (1941). Esta classificação é baseada no Índice de Aridez (Tab. 1), que corresponde à razão entre as médias anuais de precipitação e evapotranspiração potencial (MMA, 2004).

Tabela 1 - Classificação da susceptibilidade à desertificação em função do índice de aridez.

\begin{tabular}{cc}
\hline Índice de Aridez & $\begin{array}{c}\text { Suscetibilidade à } \\
\text { Desertificação }\end{array}$ \\
\hline 0,05 a 0,20 & Muito Alta \\
0,21 a 0,50 & Alta \\
0,50 a 0,65 & Moderada \\
\hline
\end{tabular}

Fonte: Matallo Jr. (2001).

O Sensoriamento Remoto, para Carvalho (2001), é sem dúvida, uma ferramenta imprescindível para o monitoramento e controle do processo de desertificação, devido à resolução espaço-temporal dos sensores, a possibilidade de uma maior escala de estudo, além da possibilidade de obtenção de dados de forma gratuita. Ainda, o monitoramento numa abordagem multi escala, permite visualizar o processo como um todo ou porções menores uma forma dinâmica e compatível com as necessidades de informação e as disponibilidades de tempo e de recursos.

As técnicas de Sensoriamento Remoto têm sido utilizadas para o estudo da desertificação, mas de acordo com Matallo Jr. (2001), existe uma ausência de métodos de estudo universalmente aceitos e ausência de métodos confiáveis para a identificação dos processos de desertificação.

Segundo Matallo Jr. (2001), um documento Brasileiro sobre indicadores de desertificação, elaborado a partir das contribuições de diferentes pesquisadores, foi proposta à FAO destacando indicadores sócio econômicos, biológicos, físicos e espectrais. A Tab. 2 apresenta os indicadores espectrais indicados no documento. 
Tabela 2 - Indicadores espectrais de desertificação.

\begin{tabular}{ll}
\hline Indicador/Parâmetro & Fonte \\
\hline 1. Refletância & Radiômetro \\
2. Índice de vegetação & NDVI, ARVI, SAVI, SARVI \\
3. Índice de área foliar & Estimativa a partir de NDVI \\
4. Temperatura de superfície & Estimativa a partir imagens de satélites (banda termal), estações meteorológicas \\
5. Emissividade aparente & Estimativa a partir de NDVI \\
6. Inércia e amplitude térmica & Estimativa a partir da temperatura de superfície \\
7. Evapotranspiração & Estimativa a partir da temperatura de superfície \\
\hline
\end{tabular}

Fonte: Adaptado de Matallo Jr. (2001).

O Índice de vegetação por diferença normalizada (NDVI), proposto por Rouse et al. (1973), referenciado na Tab. 1, para estimação de indicadores de desertificação a nível espectral é comumente empregado em trabalhos relacionados a desertificação (SANTOS; GALVÍNCIO, 2013; ARAÚJO et al., 2010; SILVA et al., 2009).

O NDVI relaciona as reflectâncias da banda do vermelho (R) e do infravermelho próximo (NIR), como descrito na Eq. 1. Este índice é aplicado na identificação da presença de vegetação verde na superfície (PONZONI; SHIMABUKURO, 2007). Desta forma, permite caracterizar a distribuição espacial da vegetação ao longo do tempo.

$\mathrm{NDVI}=(\mathrm{NIR}-\mathrm{R}) /(\mathrm{NIR}+\mathrm{R})$

Os valores de NDVI variam entre -1 a 1 (Fig. 1) onde valores negativos representam corpos hídricos, nuvens e sombra. O solo exposto ou com vegetação rala, é representado por valores positivos próximos de zero. A vegetação densa, bem desenvolvida apresenta os maiores valores de NDVI, próximos a 1 (POELKING et al., 2007).

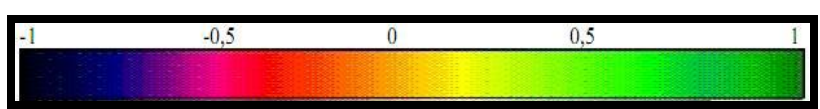

Figura 1 - Valores da razão entre as bandas do Infravermelho e Vermelho (NDVI).

Fonte: Poelking et al. (2007).

O NDVI pode expressar a condição como se apresenta a cobertura vegetal de uma região ou ainda evidenciar o nível em que se encontra a degradação.

\section{MATERIAL E MÉTODOS}

A região Semiárida do Norte de Minas Gerais localiza-se entre as coordenadas geográficas $16^{\circ} 08^{\prime} 17^{\prime \prime}$ e $15^{\circ} 36^{\prime} 20^{\prime \prime}$ de latitude Sul e $41^{\circ} 18^{\prime} 17^{\prime \prime}$ e $44^{\circ} 27^{\prime} 46^{\prime \prime}$ de longitude Oeste, é composta por 22 municípios (Fig. 2). Aproximadamente $86 \%$ desses municípios são de pequeno porte, com uma economia baseada predominantemente na atividade pecuária aliada a economia de subsistência sendo regiões com população inferior a 20 mil habitantes segundo IBGE (2010), com precipitação anual igual ou inferior a $800 \mathrm{~mm}$, e o relevo caracterizado por planaltos e depressões. 


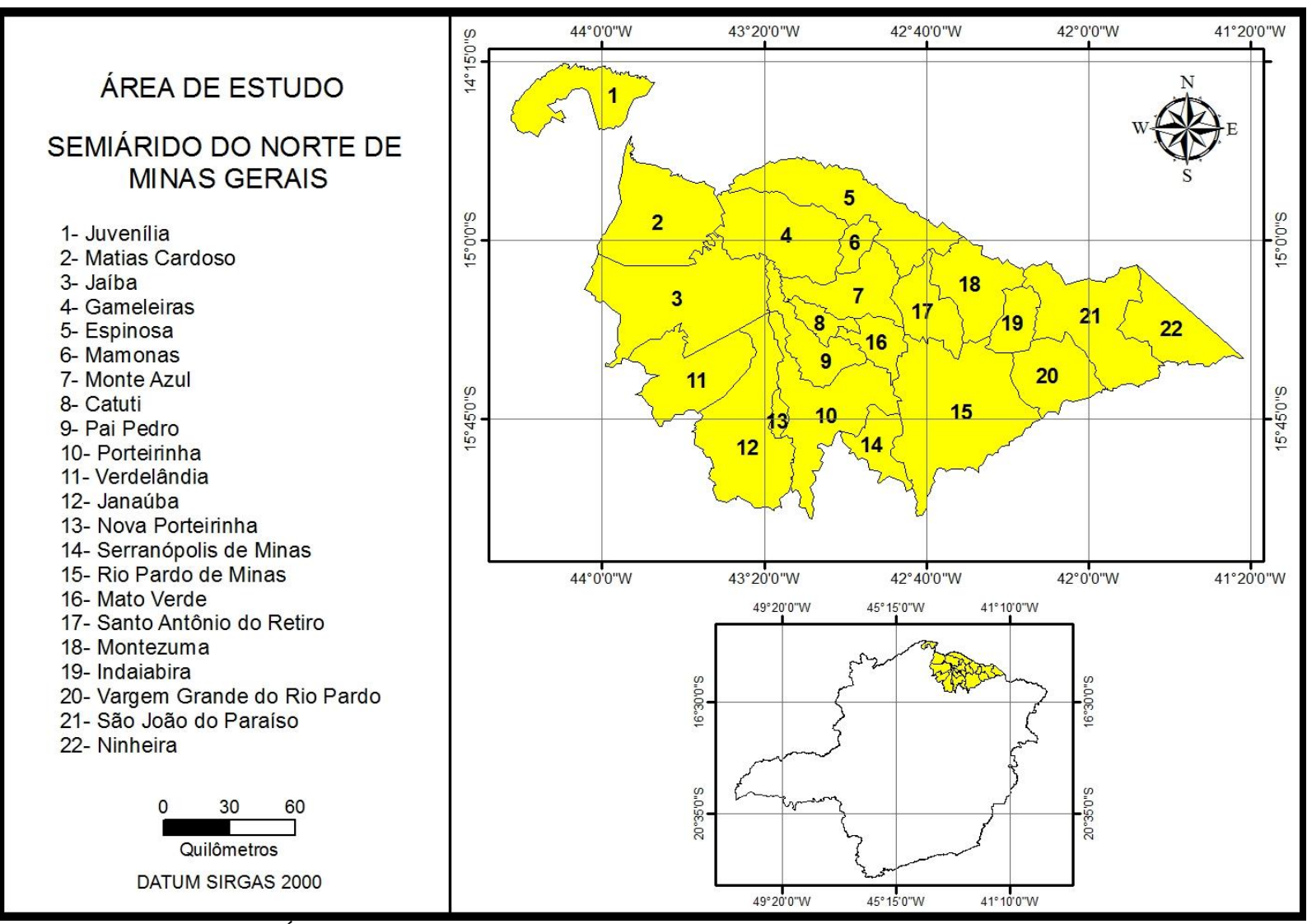

Figura 2 - Localização da Área de Estudo.

Fonte: Próprio Autor.

$\mathrm{Na}$ etapa de processamento dos dados, foi inicialmente adquiridas as imagens do satélite LANDSAT TM 5, do catálogo de imagens do Instituto Nacional de pesquisas Espacias (INPE) na data de interesse com o mínimo de cobertura de nuvens (Tab. 3).

Tabela 3 - Dados das imagens LANDSAT 5 TM

\begin{tabular}{|c|c|c|c|}
\hline Órbita/Ponto & Data da Imagem & Resolução Espacial & Período \\
\hline $217 / 071$ & $11 / 04 / 2001$ & $30 \mathrm{~m}$ & Seca \\
\hline $217 / 071$ & $23 / 06 / 2010$ & $30 \mathrm{~m}$ & Seca \\
\hline $218 / 070$ & $21 / 06 / 2001$ & $30 \mathrm{~m}$ & Seca \\
\hline $218 / 070$ & $14 / 06 / 2010$ & $30 \mathrm{~m}$ & Seca \\
\hline $218 / 071$ & $20 / 05 / 2001$ & $30 \mathrm{~m}$ & Seca \\
\hline $218 / 071$ & $01 / 08 / 2010$ & $30 \mathrm{~m}$ & Seca \\
\hline $219 / 070$ & $21 / 06 / 2001$ & $30 \mathrm{~m}$ & Seca \\
\hline $219 / 070$ & $28 / 06 / 2010$ & $30 \mathrm{~m}$ & Seca \\
\hline
\end{tabular}

Tais imagens obtidas foram registradas utilizando-se o software Sistema de Informação Georeferenciada (SPRING) (CÂMARA et al., 1996), de posse das imagens ortorretificadas GLS-Landsat adquiridas gratuitamente no catálogo de imagens do (INPE), com as respecticas caracteriscas de órbita e ponto de cada cena.

Posteriormente os valores de ND das imagens foram convertidos em radiância espectral na banda $\mathrm{i}\left(\mathrm{L}_{\mathrm{i}}\right.$ em $\left.\mathrm{Wm}^{-2} \mathrm{sr}^{-1}: \mathrm{m}^{-1}\right)$ utilizando-se os valores de radiância mínima $\left(\mathrm{Li}_{\text {min }}\right)$ e máxima $\left(\mathrm{Li}_{\text {max }}\right)$ para a banda considerada obtidos a partir da calibração absoluta de pós lançamento dos sensores LANDSAT 5 (Eq. 2).

$\mathrm{L}_{\mathrm{i}}=\mathrm{L}_{\mathrm{imin}}+\left[\left(\mathrm{L}_{\mathrm{imax}}-\mathrm{L}_{\mathrm{imin}}\right) / 255\right] * \mathrm{ND}_{\mathrm{i}}$

Onde: $\mathrm{ND}_{\mathrm{i}}=$ Nível Digital de Cinza na banda $\mathrm{i}$.

Os valores de Limin e de Limax para a imagem do LANDSAT 5 foram extraídos de Chander (2009).

Uma vez convertidos os valores de $\mathrm{NC}$ em radiância foi feita a remoção do efeito de primeira ordem da atmosfera através da metodologia DOS (Dark Object Subtraction) (CHAVEZ, 1988; 1989), 
utilizando-se planilha adaptada por Glürtler et al. (2005).

O NDVI foi utilizado como um dos indicadores do processo de desertificação, gerado pela Linguagem Espacial para Geoprocessamento Algébrico (LEGAL) do software SPRING (CÂMARA et al., 1996), e para sua interpretação foi feito um fatiamento de acordo preconizado por Santos et al. (2008), conforme a Tab. 4.

Tabela 4 - Variação de acordo com a imagem NDVI.

\begin{tabular}{|c|c|c|}
\hline Classes Temáticas & Variação do NDVI & Características \\
\hline Água e Sombra & $-0,77$ a $-0,20$ & Corpos d'água, sombreamento por nuvens ou relevo \\
\hline Áreas não vegetadas & $-0,20$ a 0,18 & $\begin{array}{l}\text { Centros urbanos, povoados, vilas e os terrenos em } \\
\text { preparo para a atividade agropecuária }\end{array}$ \\
\hline Vegegetação bastante esparsa & 0,18 a 0,23 & $\begin{array}{l}\text { Áreas destinadas às atividades de criação de animais e } \\
\text { os locais onde as plantações de culturas estão em fase } \\
\text { inicial (recém plantadas) }\end{array}$ \\
\hline Vegetação esparsa & 0,23 até 0,44 & $\begin{array}{l}\text { Culturas em estágio de crescimento e vegetais de } \\
\text { pequeno porte }\end{array}$ \\
\hline Vegetação densa & 0,44 a 0,75 & $\begin{array}{l}\text { Vegetação com estrutura bem desenvolvida ou } \\
\text { plantações em estágio próximo a colheita }\end{array}$ \\
\hline Vegetação muito densa & 0,75 a 1,00 & Vegetação densa, úmida e bem desenvolvida. \\
\hline \multicolumn{3}{|c|}{ Fonte: Adaptado de Santos et. al. (2008). } \\
\hline \multirow{4}{*}{\multicolumn{2}{|c|}{$\begin{array}{l}\text { Após a aplicação do NDVI, foi feito um mosaico } \\
\text { das } 4 \text { cenas do ano de } 2001 \text { e das } 4 \text { imagens } \\
\text { correspondentes ao ano de } 2010 \text {, dessa forma, foi } \\
\text { analisado o fatiamento do mosaico do NDVI para } \\
\text { ambos os períodos. }\end{array}$}} & $\begin{array}{l}\text { Tabela } 5 \text { - Dados de precipitação em milímetros (mm) para } \\
\text { os anos de } 2001 \text { e } 2010 .\end{array}$ \\
\hline & & $\begin{array}{l}\text { Janeiro a Agosto } \\
\text { Média mensal (mm) }\end{array}$ \\
\hline & & Ano - 2001 Ano - 2010 \\
\hline & & Janaúba \\
\hline \multirow{2}{*}{\multicolumn{2}{|c|}{ 4. RESULTADOS E DISCUSSÃO }} & Monte Azul \\
\hline & & Rio Pardo de Minas \\
\hline \multicolumn{2}{|c|}{ De acordo com Rodrigues et al. (2009) e Poelking } & Média \\
\hline
\end{tabular}
et al. (2007), uma das considerações importantes para análise de índices de vegetação é observar se a cobertura vegetal se encontra sob estresse hídrico, logo, tende a absorver menos radiação solar, aumentando sua refletância no espectro visível e a absorver mais no infravermelho próximo. Assim, a diferença entre as refletâncias nesses comprimentos de onda tendem a decrescer quanto maior o nível de estresse hídrico da cobertura vegetal.

$\mathrm{Na}$ Tab. 5 são apresentados os dados da média pluviométrica referentes aos meses de janeiro a agosto de três municípios presentes na região semiarida do Norte do Estado de Minas Gerais.

Por meio dos dados da tabela acima verificou-se uma maior disponibilidade de água para o início do ano de 2010 quando comparado aos oito primeiros meses do ano de 2001.

Nas imagens de NDVI obtidas para as oito cenas, os baixos índices de vegetação com valores próximos a zero são expressos pelas áreas com níveis de cinza mais escuros, enquanto que os níveis com maiores valores de brilho representam maiores índices de vegetação. Para demonstração, a Fig. 3 apresenta as imagens NDVI dos anos de 2001(a) e 2010(b) do município de São João do Paraíso/MG, mostrando as áreas mais claras e as mais escuras da imagem NDVI. 


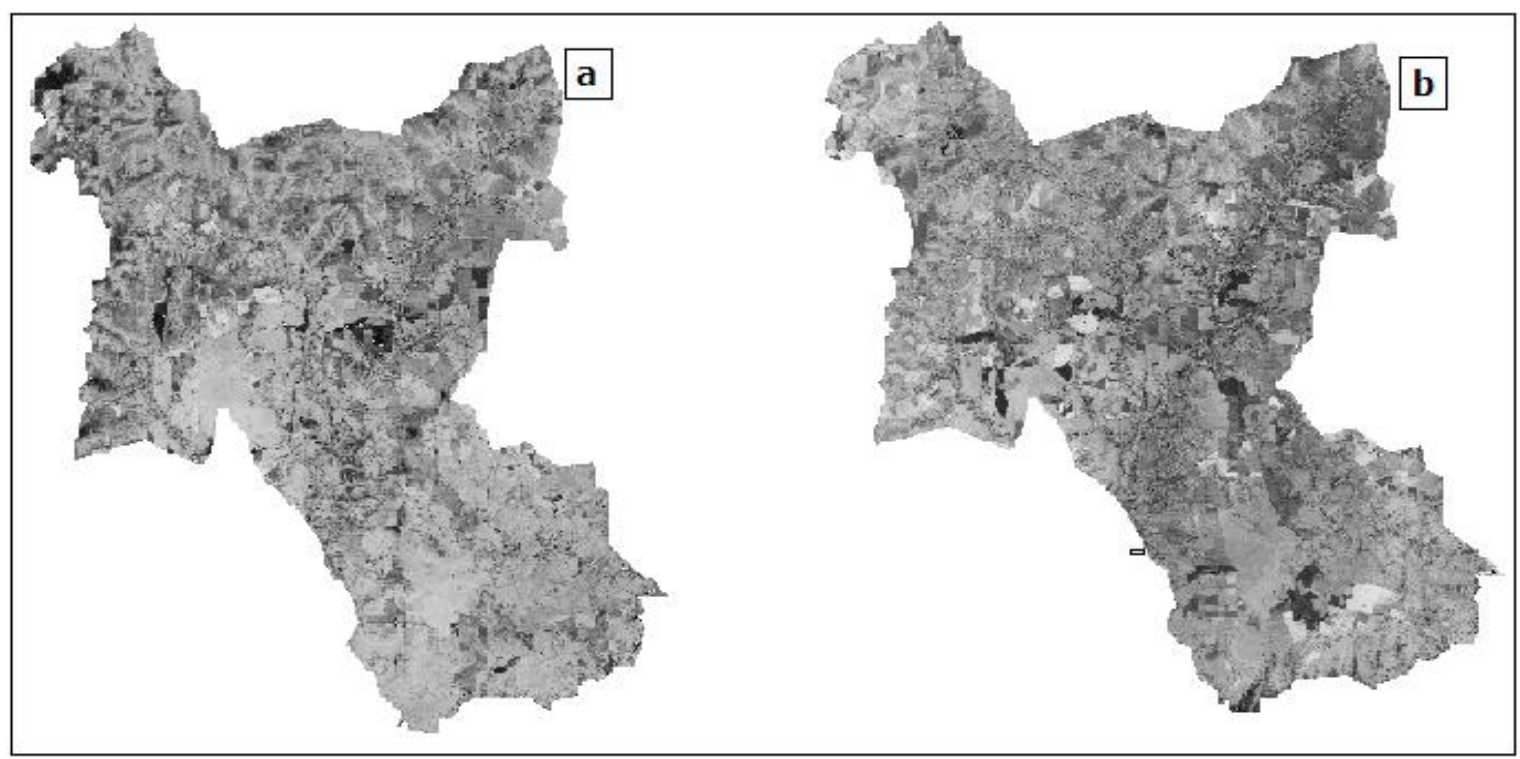

Figura 3 - Imagens do município de São João do Paraíso/MG: a) NDVI do ano 2001 e b) NDVI do ano 2010.

Na Tab. 6 são apresentados os resultados para cada categoria utilizada no fatiamento do NDVI.

Tabela 6 - Quantificação das Classes de Cobertura do solo para a área de estudo nos anos 2001 e 2010.

\begin{tabular}{|c|c|c|c|c|c|}
\hline \multirow{2}{*}{ Classes Tématicas } & \multicolumn{2}{|c|}{2001} & \multicolumn{2}{|c|}{2010} & \multirow{2}{*}{$\begin{array}{c}\text { Diferença } \\
\%\end{array}$} \\
\hline & $\left(\mathbf{K m}^{2}\right)$ & $\%$ & $\left(\mathbf{K m}^{2}\right)$ & $\%$ & \\
\hline Água e Sombra & 290 & $1 \%$ & 290 & $1 \%$ & $0 \%$ \\
\hline Áreas não vegetadas & 2.330 & $8 \%$ & 2.610 & $9 \%$ & $+1 \%$ \\
\hline Vegegetação bastante esparsa & 1.450 & $5 \%$ & 5.800 & $20 \%$ & $+15 \%$ \\
\hline Vegetação esparsa & 13.340 & $46 \%$ & 9.280 & $32 \%$ & $-14 \%$ \\
\hline Vegetação densa & 11.020 & $38 \%$ & 9.860 & $34 \%$ & $-4 \%$ \\
\hline Vegetação muito densa & 580 & $2 \%$ & 1160 & $4 \%$ & +2 \\
\hline Área total das Classes & 29.000 & $100 \%$ & 29.000 & $100 \%$ & - \\
\hline
\end{tabular}

A partir da quantificação das classes de cobertura do solo existente na área de estudo, verificou-se que para o ano de 2001 havia $2.330 \mathrm{Km}^{2}$ de áreas não vegetadas e para o ano de 2010 a mesma classe apresentou o valor $2.610 \mathrm{Km}^{2}$. Houve um aumento de $1 \%$ na área total correspondente a mesma, equivale a uma área de 280 $\mathrm{Km}^{2}$. O que significa crescimento nas áreas em processo de desertificação e degradação do solo (Tab. 6). A classe de vegetação bastante esparsa apresentou uma área de $1.450 \mathrm{Km}^{2}$ e $5.800 \mathrm{Km}^{2}$ para o ano de 2001 e 2010 respectivamente, com aumento significativo de $15 \%$ na área total, ou seja, de $4.350 \mathrm{Km}^{2}$, que pode significar aumento nas áreas de pastagens destinadas às criações animais, agricultura e desmate seletivo.

As classes de corpos hídricos não mostraram variação. Houve redução na área total nas classes de vegetação esparsa $14 \%$ e vegetação densa 4\%. A primeira passou $13.340 \mathrm{Km}^{2}$ para $9.280 \mathrm{Km}^{2}$; a segunda de $11.020 \mathrm{Km}^{2}$ para $9.860 \mathrm{Km}^{2}$ que representa a conversão de áreas preservadas para usos múltiplos.
Essas mudanças normalmente provocadas na paisagem estão associadas aos tipos de atividades desenvolvidas na área quer sejam elas: agricultura, agropecuária, mineração e práticas de irrigação que resulta em mudanças da cobertura vegetal, além dos fenômenos naturais principalmente os climáticos, e a deixa mais susceptível a se desertificar uma vez que a remoção da cobertura vegetal torna o solo desprotegido aumentando os riscos à erosão.

A classe de vegetação muito densa aumentou $2 \%$ na área total, passando de $580 \mathrm{Km}^{2}$ para $1.160 \mathrm{Km}^{2}$, esta situação indica que esse crescimento nas áreas de florestas pode estra relacionada à implantação de unidades de conservação no norte de estado, como também aumento dos reflorestamentos e culturas em estágio mais desenvolvido, como o eucalipto.

Por meio das Figs. 4 e 5 é possível verificar as categorias distribuídas espacialmente sobre a região semiarida do norte de Minas. 


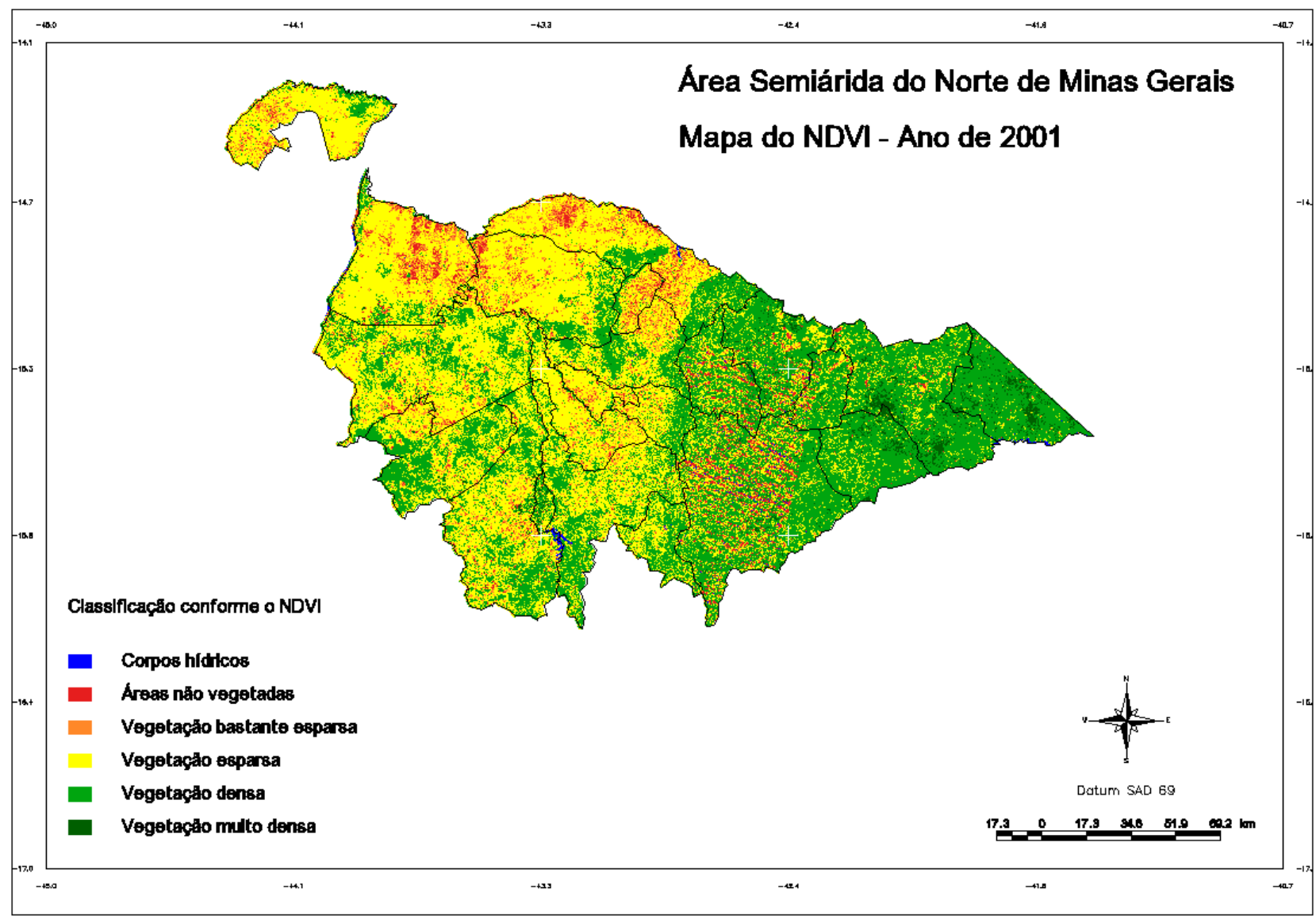

Figura 4 - Carta Temática da classificação da imagem NDVI para o ano de 2001.

Fonte: Próprio Autor. 


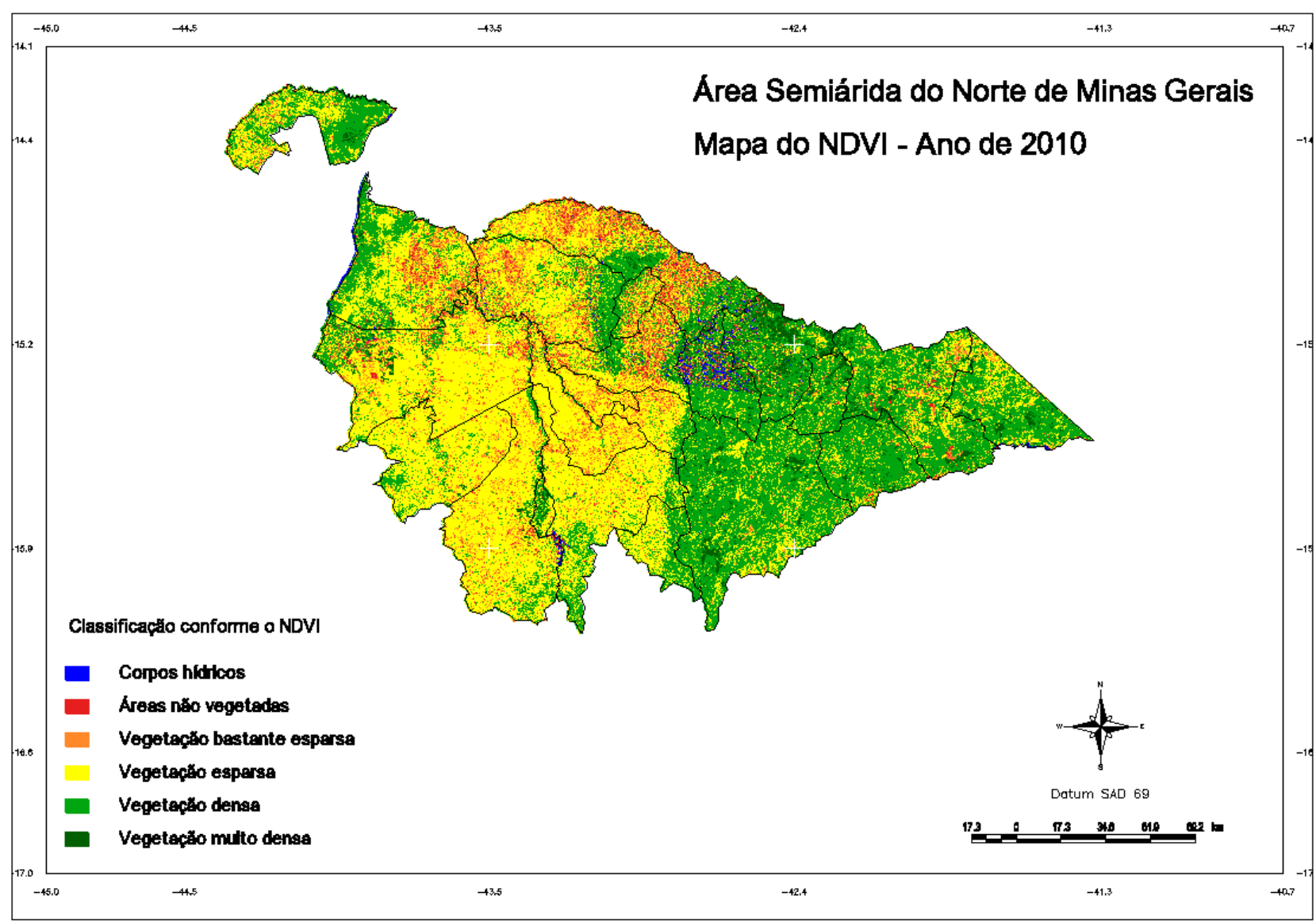

Figura 5 - Carta Temática da classificação da imagem NDVI para o ano de 2010.

Fonte: Próprio Autor

\section{CONCLUSÃO}

A utilização das técnicas de Sensoriamento Remoto apresentou viabilidade no estudo de áreas susceptíveis ao processo de desertificação, uma vez que permitiu reconhecimento de diferentes estágios vegetacionais e uma percepção do solo, sendo importante para tomada de decisão e mitigação dos efeitos da desertificação.

O software SPRING 5.2.0 mostrou eficiência para o processamento das imagens, principalmente no que diz respeito à Linguagem LEGAL na execução do NDVI.

$\mathrm{O}$ fatiamento das classes da imagem NDVI permitiu quantificar o valor pertencente a cada classe dos mapas temáticos e com isto evidenciar as condições de degradação na qual se encontra a área em estudo.

A aplicação do NDVI nas imagens permitiu caracterizar a área de estudo em termos de superfície e constatar a presença de solo exposto, indicador da desertificação em questão.

Os resultados propensos nesse trabalho mostram-se propensos na contribuição com os programas de combate a desertificação, pois permite fortalecer o conhecimento sobre este processo na região, além de apresentar a população o nível com que se encontra a degradação ambiental, onde as formas de exploração e as técnicas empregadas como meio de produção influenciam na qualidade ambiental dessas áreas, consequetemente na qualidade de vida das populações.

\section{AGRADECIMENTOS}

Os autores agradecem a Fundação Santo Agostinho, a CAPES e ao CNPq pelo apoio e incentivo à pesquisa científica.

\section{REFERENCIAS BIBLIOGRÁFICAS}

AGRITEMPO. Sistema de Monitoramento Agrometeorológico. Campinas, 2010. Disponível em: <http://www.agritempo.gov.br>. Acesso em: 10 de maio. 2013.

ARAUJO, I. R.; SILVA, H. P.; LOPES, A. S.; ALENCAR, B. P. B. SILVA, H. D. B. Cálculo de ndvi no suporte ao estudo de desertificação no município de Orocó-PE. Anais do III Simpósio Brasileiro de Ciências Geodésicas e Tecnologias da Geoinformação, Recife-PE, p. 001-006, 2010.

AUBREVILLE, A. Climats, forêts et desértification de l'Áfrique tropicale. Paris, Societé d'Editions Géographiques, Maritimes et Coloniales, 1949, 351p.

CÂMARA, G.; SOUZA, R.C.M.; FREITAS, U. M.; GARRIDO, J. C. P. (1996). SPRING: integrating remote 
sensing and GIS with object-oriented data modelling. Computers and Graphics, v. 15, n. 6, p. 13-22. Disponível em:〈http://www.dpi.inpe.br/geopro/trabalhos/spring.pdf $>$. Acesso em 02 de Março de 2013.

CARVALHO, V. C. Abordagem multiescala para o monitoramento de indicadores do processo de desertificação. Anais do XI Simpósio Brasileiro de Sensoriamento Remoto, Foz do Iguaçu, PR, Brasil. Anais... São José dos Campos: INPE, 2001, p. 1539-1551. Disponível em: <http://marte.dpi.inpe.br/col/dpi.inpe.br/lise/2001/09.24.0 9.07/doc/1539.1551.161.pdf> Acesso em: 15 de julho de 2013.

CHAVEZ JR., P.S. An improved dark-object subtraction technique for atmospheric scattering correction of multispectraldata. Remote Sensing of Environment, v. 24, p. $459-479,1988$.

CHAVEZ JR., P.S. Radiometric calibration of Landsat thematic mapper multispectral images. Photogrammetric Engineering and Remote Sensing, v. 55, p. 1285-1294, 1989.

IBGE - Instituto Brasileiro de Geografia e Estatística. CENSO2010.Disponível:<http://www.ibge.gov.br/cidade sat/painel/painel.php?codmun=314330\#> Acesso em 10 de Maio de 2013.

MATALLO JR., H. Indicadores de desertificação: histórico e perspectivas. Cadernos da UNESCO Brasil, série Meio Ambiente e Desenvolvimento, v. 2. Brasília: Unesco, 2001.

MMA (Ministério do Meio Ambiente). Programa de ação nacional de combate à Desertificação e mitigação dos efeitos da seca. Edição comemorativa 10 anos da UNCCD. Ministério do Meio Ambiente - Secretaria de Recursos Hídricos. 220p. 2004. Disponível em:< http://www.iicadesertification.org.br/attachments/categor y/8/PAN_BRASIL.pdf> Acesso em 02 de Março de 2013.

PATRÍCIO, M. C. M.; SILVA, V. M. A.; RAMOS, A. R. D. Gilbués-Núcleo de Desertificação do Piauí, Caracterização Física, Variabilidade Climática e Impactos Ambientais. POLÊM! CA, v. 11, n. 3, p. 470 a 482, 2012.

POELKING, E.L.; LAUERMANN, A.; DALMOLIN, R.S.D. Imagens CBERS na geração de NDVI no estudo da dinâmica da vegetação em período de estresse hídrico. Anais do XII Simpósio Brasileiro de Sensoriamento Remoto. Florianópolis - SC, p. 4145-4150, 2007.

PONZONI, F.J.; SHIMABUKURO, Y.E. Sensoriamento Remoto no Estudo da Vegetação. São José dos Campos, SP. Editora Parêntese, 2007.
RODRIGUES, L.; GONÇALVES, M. E.; SOUZA, S.A.G; TEIXEIRA, G.E. Especializações em atividades agropecuárias nos municípios da macrorregião Norte de Minas - MG, a partir do Índice de Concentração normalizado (ICn). In: XLII CONGRESSO DA SOCIEDADE BRASILEIRA DE ECONOMIA E SOCIOLOGIA RURAL, 2004, Cuiabá. Anais... XLII Congresso da Sociedade Brasileira de Economia e Sociologia Rural - Dinâmicas Setoriais e Desenvolvimento Regional. Cuiabá: SOBER/UERJ/UFMT/Embrapa, 2004. p. 1-20.

ROUSE, J. W.; HAAS, R. H.; SCHELL, J. A.; DEERING, D. W. Monitoring vegetation systems in the great plains with erts. In: EarthResourcesTechnologySatellite-1 Symposium, 3, 1973, Washington, D. C. Proceedings... Washington, D. C.: NASA. Goddart Space Flight Center, v. 1, p. 309-317, 1973.

SANTOS, A. M.; GALVÍNCIO, J. D. Mudanças Climáticas e Cenários de Susceptibilidade Ambiental à Desertificação em Municípios do Estado de Pernambuco. OBSERVATORIUM: Revista Eletrônica de Geografia, v.5, n.13, p. 66-83, jun. 2013.

SANTOS, M. A. et al. Aplicação do índice de vegetação por diferença normalizada (NDVI) para identificação da cobertura fitogeográfica da Bacia Hidrográfica do Rio Goiana - PE. II Simpósio de Geografia Física do NORDESTE, João Pessoa - PB, 2008. Anais... João Pessoa, PB, 2008. p.1-9.

SILVA, M. T.; SILVA, V. P. R.; MARCELINO PATRICIO, M. C.; BATISTA MARIANO, E. Análise dinâmica do processo de desertificação na região de Gilbués-PI, utilizando imagens do TM/Landsat 5. Anais do XIV Simpósio Brasileiro de Sensoriamento Remoto, Natal-RN, p. 6265-6272, 2009.

SILVA, I. A. S.; CARVALHO, J. T.; SILVA, K.A.; CHAVEIRO, E. F. Educação Ambiental: Uma Contribuição no Controle do Processo de Desertificação em Gilbués, Piauí. Anais do II Simpósio de Educação Ambiental e Transdisciplinaridade. Goiania-GO, p. 001012, 2011.

THORNTHWAITE, C.W.; HOLZMAN, B. Evaporation and transpiration. In: Climate and Man: Yearbook of Agriculture Washington: U.S. Department of Agriculture, 1941, p.545-550.

VIEIRA, F. L. R. Transposição do Rio São Franscisco e alternativas de desenvolvimento: para onde vai o semiarido nordestino?. REDES, Santa Cruz do Sul, v. 14, n. 2, p. 158-171, mai./ago. 2009. 